\title{
Covariance matrix regularization for banded toeplitz structure via frobenius-norm discrepancy
}

DOI:

10.1007/978-3-030-17519-1_9

\section{Document Version}

Accepted author manuscript

Link to publication record in Manchester Research Explorer

\section{Citation for published version (APA):}

Cui , X., Li, Z., Zhao , J., Zhang , D., \& Pan, J. (2019). Covariance matrix regularization for banded toeplitz structure via frobenius-norm discrepancy. In S. Ejaz Ahmed, F. Carvalho, \& S. Puntanen (Eds.), Matrices, statistics andbBig data: selected contributions from IWMS 2016 (pp. 111-125). Springer Nature. https://doi.org/10.1007/9783-030-17519-1_9

\section{Published in:}

Matrices, statistics andbBig data

\section{Citing this paper}

Please note that where the full-text provided on Manchester Research Explorer is the Author Accepted Manuscript or Proof version this may differ from the final Published version. If citing, it is advised that you check and use the publisher's definitive version.

\section{General rights}

Copyright and moral rights for the publications made accessible in the Research Explorer are retained by the authors and/or other copyright owners and it is a condition of accessing publications that users recognise and abide by the legal requirements associated with these rights.

\section{Takedown policy}

If you believe that this document breaches copyright please refer to the University of Manchester's Takedown Procedures [http://man.ac.uk/04Y6Bo] or contact uml.scholarlycommunications@manchester.ac.uk providing relevant details, so we can investigate your claim.

\section{OPEN ACCESS}




\title{
Covariance Matrix Regularization for Banded Toeplitz Structure via Frobenius-Norm Discrepancy
}

\author{
Xiangzhao Cui, Zhenyang Li, Jine Zhao, Defei Zhang and Jianxin Pan
}

\begin{abstract}
In many practical applications, the structure of covariance matrix is often blurred due to random errors, making the estimation of covariance matrix very difficult particularly for high-dimensional data. In this article, we propose a regularization method for finding a possible banded Toeplitz structure for a given covariance matrix $A$ (e.g., sample covariance matrix), which is usually an estimator of the unknown population covariance matrix $\Sigma$. We aim to find a matrix, say $B$, which is of banded Toeplitz structure, such that the Frobenius-norm discrepancy between $B$ and $A$ achieves the smallest in the whole class of banded Toeplitz structure matrices. As a result, the obtained Toeplitz structured matrix $B$ recoveries the underlying structure behind $\Sigma$. Our simulation studies show that $B$ is also more accurate than the sample covariance matrix $A$ when estimating the covariance matrix $\Sigma$ that has a banded Toeplitz structure. The studies also show that the proposed method works very well in regularization of covariance structure.
\end{abstract}

\section{Introduction}

Estimation of covariance matrices is important in many application fields including spectroscopy, functional magnetic resonance imaging, text retrieval, gene array, climate study and imaging analysis. This problem has been widely researched in statistics. The traditional "Burg technique", which is to find the maximum likelihood estimator of a covariance matrix, needs to provide the sample covariance matrix and pre-specify the structure of the unknown population covariance matrix [3]. However, it is well known that the sample covariance matrix performs poorly for high-dimensional data, where the number of variables is bigger than the sample size

Xiangzhao Cui, Zhenyang Li, Jine Zhao, Defei Zhang

School of Mathematics, University of Honghe, Yunnan, China. e-mail: cxzh1972@126.com

Jianxin Pan

School of Mathematics, University of Manchester, UK. e-mail: Jianxin.Pan@manchester.ac.uk 
[11]. Further, the underlying structure of the sample covariance matrix is usually blurred because of random noises from different sources.

For high-dimensional data, methods of covariance matrix regularization were developed in the literature, including hard-thresholding [9, 2], soft-thresholding and its various generalizations [18], and adaptive thresholding [4], among many others, but threshold estimators may have negative eigenvalues in finite samples. To overcome this difficulty, Rothman proposed a Lasso-type penalty based method to encourage sparsity and used a logarithmic barrier function to enforce the positivedefiniteness [17]. [20] considered an alternating direction method to ensure the positive-definiteness of Lasso penalty covariance estimator. However, all such regularization approaches require a tuning parameter, and how to choose an appropriate tuning parameter remains a very challenging problem.

For covariance matrix estimation, it has recently attracted more attentions on regularizing an estimated covariance matrix so that the underlying structure becomes clear $[14,16]$. Recently, the technique based on entropy loss function aiming to avoid the selection of tuning parameter has been proposed to regularize an estimated covariance matrix into one of the structured covariance matrices: $M A(1), C S$, $A R(1)$ and banded Toeplitz [12]. However, the technique cannot handle a highdimensional data set, since the inverse of the sample covariance matrix does not exist. Very recently, the method of regularizing an estimated covariance matrix into the one with structures $M A(1), C S, A R(1)$ and $A R M A(1,1)$ via Frobenius-norm discrepancy was developed by [6,7]. Although this method avoids the use of the inverse of the sample covariance matrix, it only considered the above four candidate covariance structures, that is, $M A(1), C S, A R(1), A R M A(1,1)$. It is well known that banded Toeplitz covariance matrices are very common in practice, in particular, it is commonly used in time series. For example, in signal processes the covariance matrix of Gauss-Markov random process or cyclostationary process often displays a banded Toeplitz structure $[13,19,5]$. On the other hand, all the four structures, i.e., $M A(1), C S, A R(1)$ and $A R M A(1,1)$, are a special case of banded Toeplitz structures.

In order to study a more general structure, in this paper we consider the regularization problem for covariance matrix with banded Toeplitz structures. The $m \times m$ covariance matrix is of the form

$$
B\left(\sigma^{2}, c_{1}, \cdots, c_{p}\right)=\sigma^{2}\left[\begin{array}{cccccccc}
1 & c_{1} & c_{2} & \cdots & c_{p} & 0 & \cdots & 0 \\
c_{1} & 1 & c_{1} & \ddots & \ddots & \ddots & \ddots & \vdots \\
c_{2} & c_{1} & 1 & \ddots & \ddots & \ddots & \ddots & 0 \\
\vdots & \ddots & \ddots & \ddots & \ddots & \ddots & \ddots & c_{p} \\
c_{p} & \ddots & \ddots & \ddots & \ddots & \ddots & \ddots & \vdots \\
0 & \ddots & \ddots & \ddots & \ddots & 1 & c_{1} & c_{2} \\
\vdots & \ddots & \ddots & \ddots & \ddots & c_{1} & 1 & c_{1} \\
0 & \cdots & 0 & c_{p} & \cdots & c_{2} & c_{1} & 1
\end{array}\right]
$$


where $\sigma^{2}>0, c_{1}, c_{2}, \ldots, c_{p}(m>p)$ are nonzero and all other off-diagonal elements are zero. Define $q(t)=1+2 \sum_{k=1}^{p} c_{k} \cos (k t)$, then $B$ is positive-definite if and only if $q(t) \geq 0, q(t) \not \equiv 0$, for all $t \in R[15]$.

The outline of the paper is as follows. In Section 2, we transform the regularization problem into an optimization problem in numerical analysis and explore its general properties. In Section 3, we discuss the problem of finding the optimal structure from a class of banded Toeplitz structures, in the sense of minimizing the square of the Frobenius-norm discrepancy. In Section 4, we conduct simulation studies to measure the performance and effectiveness of the proposed approach. In Section 5, a brief discussion is provided.

\section{Problem of interest}

In order to transform the regularization problem into an optimization problem, we suppose $A$ is an available $m \times m$ estimator of a covariance matrix, for example, the sample covariance matrix. Note that it may also be one of those obtained by using SQRT-Lasso [1], matrix-logarithm transformation [8] and thresholding principal orthogonal complements [10] among many others. Let $\Omega$ be the set of all $m \times m$ positive definite covariance matrices with banded Toeplitz structure. A discrepancy between the given covariance matrix $A$ and the set $\Omega$ is defined by

$$
D(A, \Omega):=\min _{B \in \Omega} L(A, B),
$$

where $L(A, B)$ is a measure of the distance between the two $m \times m$ matrices $A$ and $B$, defined by the square of the Frobenius-norm. In other words,

$$
L(A, B):=\operatorname{tr}\left((A-B)^{T}(A-B)\right) .
$$

Note that $f(B):=L(A, B)=\operatorname{tr}\left((A-B)^{T}(A-B)\right)$ is a strictly convex function of $B$ [7]. Also, the set $\Omega$ is obviously convex. Since $\Omega$ is the set of all positive definite matrices having a banded Toeplitz structure, the optimization problem in (2) is convex and so it has a unique solution.

The idea is that, in this set $\Omega$, the matrix $B$ which satisfies the above equality can be considered as the regularized version of $A$. In other words, the matrix $B$ with a banded Toeplitz structure is considered to have the underlying structure of $\Omega$.

We remark that the matrix $A$ does not require a non-singularity, meaning that it applies to the case when the matrix $A$ is singular, for example, $A$ is the sample covariance matrix for high-dimensional data. In other words, even if the given covariance matrix $A$ is singular, we can find a covariance matrix $B$ which has a nonsingular banded Toeplitz structure, such that the $F$-norm discrepancy function $L(A, B)$ achieves its smallest among the class of banded Toeplitz matrices. 


\section{Solution of problem}

The matrix $B$ in (1) can be rewritten as

$$
B\left(\sigma^{2}, c_{1}, \cdots, c_{p}\right)=\sigma^{2}\left(I+\sum_{i=1}^{p} c_{i} T_{i}\right)
$$

where $T_{i}$ is a symmetric matrix with ones on the $i$ th superdiagonal and subdiagonal and zeros elsewhere.

The discrepancy function in (3) is now

$$
f\left(\sigma^{2}, c_{1}, \cdots, c_{p}\right)=\operatorname{tr}\left(A A^{T}\right)+\sigma^{4}\left(m+2 \sum_{i=1}^{p}(m-i) c_{i}^{2}\right)-2 \sigma^{2}\left(\operatorname{tr}(A)+\sum_{i=1}^{p} c_{i} \operatorname{tr}\left(A T_{i}\right)\right) .
$$

It follows that

$$
\nabla f:=\left[\begin{array}{c}
\frac{\partial f}{\partial\left(\sigma^{2}\right)} \\
\frac{\partial f}{\partial c_{1}} \\
\vdots \\
\frac{\partial f}{\partial c_{p}}
\end{array}\right]=\left[\begin{array}{c}
2 \sigma^{2}\left(m+2 \sum_{i=1}^{p}(m-i) c_{i}^{2}\right)-2\left(\operatorname{tr}(A)+\sum_{i=1}^{p} c_{i} \operatorname{tr}\left(A T_{i}\right)\right) \\
4 \sigma^{4}(m-1) c_{1}-2 \sigma^{2} \operatorname{tr}\left(A T_{1}\right) \\
\vdots \\
4 \sigma^{4}(m-p) c_{p}-2 \sigma^{2} \operatorname{tr}\left(A T_{p}\right)
\end{array}\right]
$$

and

$$
\begin{aligned}
& \nabla^{2} f:=\left[\begin{array}{cccc}
\frac{\partial^{2} f}{\partial\left(\sigma^{2}\right)^{2}} & \frac{\partial^{2} f}{\partial\left(\sigma^{2}\right) \partial c_{1}} & \cdots & \frac{\partial^{2} f}{\partial\left(\sigma^{2}\right) \partial c_{p}} \\
\frac{\partial^{2} f}{\partial c_{1} \partial\left(\sigma^{2}\right)} & \frac{\partial^{2} f}{\partial c_{1}^{2}} & \cdots & \frac{\partial^{2} f}{\partial c_{1} \partial c_{p}} \\
\cdots & \cdots & \cdots & \cdots \\
\frac{\partial^{2} f}{\partial c_{p} \partial\left(\sigma^{2}\right)} & \frac{\partial^{2} f}{\partial c_{p} \partial c_{1}} & \cdots & \frac{\partial^{2} f}{\partial c_{p}^{2}}
\end{array}\right] \\
& =\left[\begin{array}{cccc}
2 m+4 \sum_{i=1}^{p}(m-i) c_{i}^{2} & 8 \sigma^{2}(m-1) c_{1}-2 \operatorname{tr}\left(A T_{1}\right) & \cdots & 8 \sigma^{2}(m-p) c_{p}-2 \operatorname{tr}\left(A T_{p}\right) \\
8 \sigma^{2}(m-1) c_{1}-2 \operatorname{tr}\left(A T_{1}\right) & 4 \sigma^{4}(m-1) & \ldots & 0 \\
\ldots & \cdots & \ldots & \ldots \\
8 \sigma^{2}(m-p) c_{p}-2 \operatorname{tr}\left(A T_{p}\right) & 0 & \ldots & 4 \sigma^{4}(m-p)
\end{array}\right] .
\end{aligned}
$$

Hence the stationary points $\left(\sigma^{2}, c_{1}, \cdots, c_{p}\right)$ must satisfy the following equations 


$$
\left\{\begin{array}{l}
m \sigma^{2}+2 \sigma^{2} \sum_{i=1}^{p}(m-i) c_{i}^{2}-\operatorname{tr}(A)-\sum_{i=1}^{p} c_{i} \operatorname{tr}\left(A T_{i}\right)=0 \\
2 \sigma^{2}(m-1) c_{1}-\operatorname{tr}\left(A T_{1}\right)=0 \\
\cdots \cdots \cdots \cdots \cdots \cdots \cdots \cdots \cdots \cdots \cdots \\
2 \sigma^{2}(m-p) c_{p}-\operatorname{tr}\left(A T_{p}\right)=0 .
\end{array}\right.
$$

Thus a unique stationary point is

$$
\left\{\begin{array}{l}
\sigma^{2}=\frac{\operatorname{tr}(A)}{m} \\
c_{1}=\frac{m \operatorname{tr}\left(A T_{1}\right)}{2(m-1) \operatorname{tr}(A)} \\
\ldots \ldots \ldots \ldots \ldots \ldots \\
c_{p}=\frac{m \operatorname{tr}\left(A T_{p}\right)}{2(m-p) \operatorname{tr}(A)}
\end{array}\right.
$$

Since

$$
\left.\nabla^{2} f\right|_{\left(\sigma^{2}, c_{1}, \cdots, c_{p}\right)}:=\left[\begin{array}{cccc}
2 m+4 \sum_{i=1}^{p}(m-i) c_{i}^{2} & 4 \sigma^{2}(m-1) c_{1} & \cdots & 4 \sigma^{2}(m-p) c_{p} \\
4 \sigma^{2}(m-1) c_{1} & 4 \sigma^{4}(m-1) & \ldots & 0 \\
\ldots & \ldots & \ldots & \ldots \\
4 \sigma^{2}(m-p) c_{p} & 0 & \ldots & 4 \sigma^{4}(m-p)
\end{array}\right],
$$

the $k \times k$ leading principal minor of matrix $\left.\nabla^{2} f\right|_{\left(\sigma^{2}, c_{1}, \cdots, c_{p}\right)}$ is given by

$$
W_{k}= \begin{cases}2 m+4 \sum_{i=1}^{p}(m-i) c_{i}^{2} & k=1 \\ \left(2 m+4 \sum_{i=k}^{p}(m-i) c_{i}^{2}\right) \prod_{i=1}^{k-1} 4 \sigma^{4}(m-i) & k=2, \cdots, p \\ 2 m \prod_{i=1}^{p} 4 \sigma^{4}(m-i) & k=p+1 .\end{cases}
$$

Recalling that $\sigma^{2}>0, p \leq m-1, c_{1}, c_{2}, \ldots, c_{p}$ are nonzero, we have $W_{k}>0$. The Hessian matrix $\left.\nabla^{2} f\right|_{\left(\sigma^{2}, c_{1}, \cdots, c_{p}\right)}$ is then positive definite, so that its stationary point is really a minimum point. This point, however, may be a local minima of $f(B)$. It is well-known that if the function is convex then the local minimum is actually the global minimum, but it is difficult to check if $f(B)$ is convex with respect to $\left(c_{1}, \cdots, c_{p}\right)$ here due to its complexity. We suggest to compare the function values at all the local minima so that the global minimum can be achieved.

We summarize the discussion above in the following theorem. 
Theorem 1. For a given estimator $A$ of an $m \times m$ covariance matrix, define $f(B):=$ $L(A, B)$ where $B$ is a positive definite covariance matrix with a banded Toeplitz structure. Then the local or global minimum of $f(B)$ can be achieved as the solution of (5).

\section{Simulation studies}

To check the actual performance of the proposed regularization method, we carry out intensive simulation studies in this section. All the calculations are done using MATLAB R2012b, and we apply fzero and fsolve to find roots.

In the process of the simulation, we first generate an $m \times m$ covariance matrix $\Sigma$ which has one of the following structures: order-1 moving average structure $(M A(1))$, compound symmetry structure $(C S)$, order-1 autoregressive structure $(A R(1))$, order-1 autoregressive moving average structure $(A R M A(1,1))$, cf. [6, 7], and a banded Toeplitz structure. We assume an $m$ dimensional zero mean vector $\mu=\mathbf{0}$. We take a random sample of size $n$ from multivariate normal distribution $N_{m}(\mathbf{0}, \Sigma)$ and then calculate the sample covariance matrix $A$. In the end, we find matrix $B$ which has a banded Toeplitz structure mentioned above, achieving the minimum of the Frobenius-norm.

We need to state the following facts.

1. We only need to find the desired matrix among the ones which have the same structure as the correct covariance structure, because for the cases of $M A(1)$, $C S, A R(1)$ or $A R M A(1,1)[6,7]$ already showed that the matrix $B$ that has the minimum F-norm remains the same structure as the true covariance matrix.

2. Since the function $L(A, B)$ measures the absolute difference between matrices $A$ and $B$, it can make the value of $L(A, B)$ too large. To reduce the influence of the dimension of covariance matrix and its elements on $L(A, B)$, we re-define the following function to replace $L(A, B)$

$$
L^{*}(A, B):=\operatorname{tr}\left((A-B)^{T}(A-B)\right) / \operatorname{tr}\left(A^{T} A\right),
$$

which does not affect the finding of the optimal matrix $B$.

We will use the following notations:

- $\Sigma$ : the true covariance matrix being tested;

- $A$ : the covariance matrix obtained from sample;

- $B$ : the matrix which minimizes $L^{*}(A, B)$ and has a structure of $M A(1), C S, A R(1)$, $\operatorname{ARMA}(1,1)$ or banded Toeplitz;

- $L_{\Sigma, A}^{*}, L_{A, B}^{*}$ and $L_{\Sigma, B}^{*}$ : the difference functions $L^{*}(\Sigma, A), L^{*}(A, B)$ and $L^{*}(\Sigma, B)$, respectively.

For $\Sigma$ having $M A(1), C S$ or $A R(1)$ structure, we set the sample size $n=100$, matrix dimension $m=10,20,50,100,200,500,1000, \sigma^{2}=0.5,1,2,4$, parameter $c=0.25,0.5,0.75$. For $\Sigma$ having $A R M A(1,1)$ structure, in addition to the above 
values, we set $r=0.1,0.35,0.6$ when $c=0.25 ; r=0.2,0.45,0.75$ when $c=0.5$; and $r=0.25,0.5,0.8$ when $c=0.75$.

We apply the method proposed in $[6,7]$ to find the matrix $B$ which has $M A(1)$, $C S, A R(1)$ or $\operatorname{ARMA}(1,1)$ structure and has the minimum F-norm difference. We also apply the method proposed in this paper for the case when the matrix has a banded Toeplitz structure with $p=m-1$.

Table 1-12 gives the average results after 100 run simulations. In each of those tables, the first column provides the structure of the true covariance matrix $\Sigma$, the second column presents the F-norm difference between the sample covariance matrix $A$ and $\Sigma$; the third and forth columns give the F-norm differences between $B$ and $A, \Sigma$, respectively, where $B$ is obtained by using the same structure as $\Sigma$; the fifth and sixth columns provide the F-norm differences between $B$ and $A, \Sigma$, respectively, where $B$ is obtained by assuming a banded Toeplitz structure.

To save space, in Tables 1-12 we only report simulation results for $n=50,100,500$ and 1000 . Other results are very similar to these reported. From these tables, we can draw the following observations.

1. For the matrix $B$ obtained by using either the same structure as $\Sigma$ or a banded Toeplitz structure, the F-norm discrepancy between $B$ and the real covariance matrix $\Sigma$ is very small. It implies that the resulting covariance matrices have the same structure, and the minor difference is mainly due to random errors and computing errors.

2. There is no doubt that the matrix $B$ obtained using a banded Toeplitz structure has a smaller F-norm difference than those using $M A(1), C S, A R(1)$ or $\operatorname{ARMA}(1,1)$ structures. This is because all those four cases are special cases of banded Toeplitz structures. The bigger the definition area, the smaller the optimal function value. However, the difference in their F-norms is rather small, implying that the identified Toeplitz structure actually reduces to one of the special structures.

3. The F-norm discrepancy between $B$ obtained from our proposed method and the true covariance matrix $\Sigma$ is smaller than the F-norm discrepancy between $A$ and $\Sigma$. It implies that the proposed method reduces random noises, so that a better estimator of the covariance matrix is obtained.

Since the real covariance matrix $\Sigma$ is unknown in practice, the F-norm discrepancy between $B$ and the sample covariance matrix $A$ becomes very important in finding the underlying structure of $\Sigma$.

For $\Sigma$ having a banded Toeplitz structure, apart from the above values of $n, m, \sigma^{2}$ we actually randomly generate parameters $c_{1}, c_{2}, \cdots, c_{p}$ from uniform distribution $U(0,1)$ but require the positive definiteness of covariance matrix $\Sigma$, where we choose $p=m-1$. The results are presented in Table 13, where similarly each value is the average after repeating 100 times of simulations. The first column gives the dimension of the true covariance matrix $\Sigma$, the second column provides the F-norm discrepancy between the sample covariance matrix $A$ and $\Sigma$, the rest columns present the F-norm discrepancy between $A, \Sigma$ and the matrix $B$ obtained using the specified structures indicated in the second line, respectively. 
Form Table 13 we make conclusions below.

1. The matrix $B$ having the minimum F-norm difference satisfies $L^{*}(\Sigma, B)<L^{*}(\Sigma, A)$, meaning that the estimator $B$ obtained using the proposed regularization method removes the random noise in the sample covariance matrix $A$, so that a better estimator of the covariance matrix $\Sigma$ is obtained.

2. The matrix $B$ having the minimum F-norm difference and obtained by using a banded Toeplitz structure has a small value of $L^{*}(\Sigma, B)$. Hence, we can really find the structure of the true covariance matrix $\Sigma$ through $B$ which uses the information of the sample covariance matrix $A$.

It is worth noting that conclusions made in this section are valid for all the studied structures of $\Sigma$ and all the settings of parameters $n, m, \sigma^{2}, c, r, c_{1}, c_{2}, \cdots, c_{p}$. Thus, the proposed method is reliable in this sense. Especially, the proposed regularization method works very well even for high-dimensional covariance matrix, where we considered the cases for the sample size $n=100$ and the dimension of the covariance matrix $m=100,200,500$ and 1000 , respectively.

\section{Discussion}

For an estimator $A$ of the covariance matrix $\Sigma$, we propose a new regularization method to find the matrix $B$ that has a banded Toeplitz structure. By doing so, we not only find the structure of $\Sigma$ but also a better estimator $B$ in the sense of Fnorm difference function. The method reveals the underlying covariance/correlation structure of the random process, and also reduces random noises.

We choose the sample covariance matrix $A$ as the estimator of $\Sigma$ in the simulations. Actually, we do not always have to choose the sample covariance matrix. Theoretically, the matrix $A$ can be taken as any other reasonable estimators obtained using certain statistical method. Once matrix $A$ is obtained, we can always do the regularization using the proposed method, so that the estimation can be improved in the sense of F-norm difference. Note that there is no strict condition imposed to the symmetric matrix $A$, which may be singular and/or high-dimensional. Also, the distribution of data which formulates the estimator $A$ might be unknown. Hence the proposed method is more flexible in this sense.

Our simulation studies only considered the data having Gaussian distribution and the paper only studied the F-norm discrepancy. In practice, there are other distributions and other loss functions such as quadratic loss function. The study of such issues may be challenging but important. We will investigate this in our follow-up work. 


\section{Acknowledgements}

We gratefully acknowledge very constructive comments and suggestions by the Editor and one anonymous reviewer, which leads to significant improvements to the paper.

\section{References}

1. A. Belloni, V. Chernozhukov and L. Wang (2012). Square-root lasso: Pivotal recovery of sparse signals via conic programming. Biometrika. 98, 791-806.

2. P. Bickel, E. Levina (2008). Covariance regularization by thresholding. Ann Statist. 36, $2577-$ 2604.

3. J. P. Burg, D. G. Luenberger, and D. L.Wenger (1982). Estimation of structured covariance matrices. Proceedings of the IEEE. 70(9), 963-974.

4. T. Cai and W. Liu (2011). Adaptive thresholding for sparse covariance estimation. J Am Stat Assoc. 106, 672-684.

5. M. Chakraborty (1998). An efficient algorithm for solving general periodic Toeplitz systems. IEEE Trans. Signal Process. 46(3), 784-787.

6. X. Cui, C. Li, J. Zhao, L. Zeng, D. Zhang, J. Pan (2016). Regularization for high-dimensional covariance matrix. Spec. Matrices. 4, 189-201.

7. X. Cui, C. Li, J. Zhao, L. Zeng, D. Zhang, J. Pan (2016). Covariance structure regularization via Frobenius-norm discrepancy. Linear Algebra and its Applications. 510, 124-145.

8. X. Deng and K. Tsui (2013). Penalized covariance matrix estimation using a matrix-logarithm transformation. J Comput Stat Graph. 22, 494-512.

9. N. El Karoui (2008). Operator norm consistent estimation of large dimensional sparse covariance matrices. Ann Statist. 36, 2712-2756.

10. J. Fan, Y. Liao and M. Mincheva (2013). Large covariance estimation by thresholding principal orthogonal complements. J Roy Stat Soc B. 75, 656-658.

11. I. M. Johnstone (2001). On the distribution of the largest eigenvalue in principal components analysis. Ann. Statist. 29, 295-327.

12. L. Lin, N. J. Higham and J. Pan (2014). Covariance structure regularization via entropy loss function. Computational Statistics \& Data Analysis. 72, 315-327.

13. J. M. F. Moura and N. Balram (1992). Recursive structure of noncausal gauss-markov random fields, IEEE Trans. Inform. Theory. 38(2), 334-354.

14. J. Pan and G. Mackenzie (2003). On modelling mean-covariance structures in longitudinal studies. Biometrika. 90(1), 239-244.

15. S. V. Parter (1962). An observation on the numerical solution of difference equations and a theorem of Szegö. Numerische Mathematik. 4, 293-295.

16. M. Pourahmadi (1999). Joint mean-covariance models with applications to longitudinal data: Unconstrained parameterisation. Biometrika. 86(3), 677-690.

17. A. Rothman (2012). Positive definite estimators of large covariance matrices. Biometrika. 99, 733-740.

18. A. Rothman, E. Levina, J. Zhu (2009). Generalized thresholding of large covariance matrices. J Am Stat Assoc. 104, 177-186.

19. J. W. Woods (1972). Two-dimensional discrete markovian fields, IEEE Trans. Inform. Theory. 18(2), 232-240.

20. L. Xue, S. Ma, H. Zou (2012). Positive definite $\ell_{1}$ penalized estimation of large covariance matrices (2012). J Am Stat Assoc. 107, 1480-1491. 
Table 1 Simulation results with $m=50 ; c=0.25$.

\begin{tabular}{|c|c|c|c|}
\hline \multirow{2}{*}{\multicolumn{2}{|c|}{$\sigma^{2}=0.50$}} & \multicolumn{2}{|c|}{ B } \\
\hline & & Same structure & Toeplitz \\
\hline$\Sigma$ & $L_{\Sigma . A}^{*}$ & $\begin{array}{|ll|}L_{A, B}^{*} & L_{\Sigma, B}^{*} \\
\end{array}$ & $L_{A, B}^{*} \quad L_{\Sigma, B}^{*}$ \\
\hline $\mathrm{MA}(1)$ & 0.3144 & $\begin{array}{llll}0.3140 & 0.0004\end{array}$ & 0.30100 .0134 \\
\hline $\mathrm{CS}$ & 0.1303 & 0.11050 .0198 & 0.10740 .0229 \\
\hline $\mathrm{AR}(1)$ & 0.3153 & $\begin{array}{|ll|}0.3145 & 0.0008 \\
\end{array}$ & 0.30120 .0141 \\
\hline ARMA-r $=0.1$ & 0.3350 & $\begin{array}{|lll|}0.3342 & 0.0009 \\
\end{array}$ & 0.32140 .0136 \\
\hline ARMA-r $=0.35$ & 0.2919 & 0.29080 .0011 & 0.27800 .0140 \\
\hline ARMA-r $=0.6$ & 0.2304 & $\begin{array}{|ll|}0.2292 & 0.0012 \\
\end{array}$ & 0.21470 .0157 \\
\hline \multirow{2}{*}{\multicolumn{2}{|c|}{$\sigma^{2}=1$}} & \multicolumn{2}{|c|}{$\mathrm{B}$} \\
\hline & & Same structure & Toeplitz \\
\hline$\Sigma$ & $L_{\Sigma, A}^{*}$ & $\begin{array}{|ll|}L_{A, B}^{*} & L_{\Sigma, B}^{*} \\
\end{array}$ & $L_{A, B}^{*} \quad L_{\Sigma, B}^{*}$ \\
\hline $\mathrm{MA}(1)$ & 0.3134 & $\begin{array}{|ll|}0.3128 & 0.0005\end{array}$ & 0.29980 .0136 \\
\hline $\mathrm{CS}$ & 0.1191 & $\begin{array}{|ll|}0.1018 & 0.0173 \\
\end{array}$ & 0.09890 .0202 \\
\hline $\mathrm{AR}(1)$ & 0.3115 & $\begin{array}{|ll|}0.3107 & 0.0008 \\
\end{array}$ & 0.29760 .0139 \\
\hline ARMA-r $=0.1$ & 0.3367 & $\begin{array}{|ll|}0.3359 & 0.0007 \\
\end{array}$ & 0.32340 .0133 \\
\hline ARMA-r $=0.35$ & 0.2923 & $\begin{array}{|ll|}0.2911 & 0.0012 \\
\end{array}$ & 0.27810 .0142 \\
\hline ARMA-r $=0.6$ & 0.2279 & 0.22660 .0013 & 0.21290 .0150 \\
\hline \multirow{2}{*}{\multicolumn{2}{|c|}{$\sigma^{2}=2$}} & \multicolumn{2}{|c|}{\begin{tabular}{|c|}
$\mathrm{B}$ \\
\end{tabular}} \\
\hline & & Same structure & Toeplitz \\
\hline$\Sigma$ & $L_{\Sigma, A}^{*}$ & $\begin{array}{|ll|}L_{A, B}^{*} & L_{\Sigma, B}^{*} \\
\end{array}$ & $\begin{array}{ll}L_{A, B}^{*} & L_{\Sigma, B}^{*}\end{array}$ \\
\hline MA(1) & 0.3162 & $0.3156 \quad 0.0005$ & 0.30230 .0138 \\
\hline $\mathrm{CS}$ & 0.1185 & 0.10360 .0149 & 0.10070 .0178 \\
\hline $\mathrm{AR}(1)$ & 0.3137 & $\begin{array}{|ll|}0.3131 & 0.0006 \\
\end{array}$ & 0.30060 .0131 \\
\hline ARMA-r $=0.1$ & 0.3354 & $\begin{array}{|ll|}0.3345 & 0.0010\end{array}$ & 0.32160 .0138 \\
\hline ARMA-r $=0.35$ & 0.2919 & $0.2908 \quad 0.0011$ & 0.27810 .0138 \\
\hline ARMA-r $=0.6$ & 0.2297 & $0.2283 \quad 0.0014$ & 0.21400 .0157 \\
\hline \multirow{2}{*}{\multicolumn{2}{|c|}{$\sigma^{2}=4$}} & \multicolumn{2}{|c|}{ B } \\
\hline & & Same structure & Toeplitz \\
\hline$\Sigma$ & $L_{\Sigma, A}^{*}$ & $\begin{array}{|ll|}L_{A, B}^{*} & L_{\Sigma, B}^{*} \\
\end{array}$ & $L_{A, B}^{*} \quad L_{\Sigma, B}^{*}$ \\
\hline MA(1) & 0.3155 & $\begin{array}{|ll|}0.3149 & 0.0005 \\
\end{array}$ & $\begin{array}{lll}, D & 2, i \\
\end{array}$ \\
\hline $\mathrm{CS}$ & 0.1233 & $\begin{array}{|lll|}0.1064 & 0.0170\end{array}$ & 0.10350 .0199 \\
\hline $\mathrm{AR}(1)$ & 0.3129 & $\begin{array}{|lll|}0.3120 & 0.0009 \\
\end{array}$ & 0.29860 .0143 \\
\hline ARMA-r $=0.1$ & 0.3345 & 0.33360 .0009 & 0.32050 .0140 \\
\hline ARMA-r $=0.35$ & 0.2932 & $\begin{array}{|ll|}0.2920 & 0.0013 \\
\end{array}$ & 0.27860 .0146 \\
\hline ARMA-r $=0.6$ & 0.2284 & 0.22700 .0014 & 0.21330 .0151 \\
\hline
\end{tabular}


Table 2 Simulation results with $m=50 ; c=0.5$.

\begin{tabular}{|c|c|c|c|}
\hline \multirow{2}{*}{\multicolumn{2}{|c|}{$\sigma^{2}=0.50$}} & \multicolumn{2}{|c|}{ B } \\
\hline & & \begin{tabular}{|l|} 
Same structure \\
\end{tabular} & Toeplitz \\
\hline$\Sigma$ & $L_{\Sigma, A}^{*}$ & 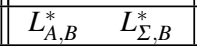 & $\begin{array}{ll}L_{A, B}^{*} & L_{\Sigma, B}^{*} \\
\end{array}$ \\
\hline MA(1) & 0.2584 & 0.25770 .0006 & 0.24380 .0146 \\
\hline $\mathrm{CS}$ & 0.0500 & 0.02840 .0216 & 0.02780 .0222 \\
\hline $\mathrm{AR}(1)$ & 0.2399 & 0.23830 .0016 & 0.22470 .0152 \\
\hline ARMA-r=0.2 & 0.3184 & $\begin{array}{|ll|}0.3173 & 0.0012 \\
\end{array}$ & 0.30530 .0131 \\
\hline ARMA-r=0.45 & 0.2539 & 0.25240 .0016 & 0.23970 .0143 \\
\hline ARMA-r=0.75 & 0.1772 & $\begin{array}{|ll|}0.1749 & 0.0023 \\
\end{array}$ & 0.16070 .0165 \\
\hline \multirow{2}{*}{\multicolumn{2}{|c|}{$\sigma^{2}=1$}} & \multicolumn{2}{|c|}{\begin{tabular}{|c|} 
B \\
\end{tabular}} \\
\hline & & Same structure & Toeplitz \\
\hline$\Sigma$ & $L_{\Sigma, A}^{*}$ & $\begin{array}{|ll|}L_{A, B}^{*} & L_{\Sigma, B}^{*} \\
\end{array}$ & $\begin{array}{ll}L_{A, B}^{*} & L_{\Sigma, B}^{*}\end{array}$ \\
\hline $\mathrm{MA}(1)$ & 0.2590 & \begin{tabular}{|ll|l|}
0.2582 & 0.0007 \\
\end{tabular} & 0.24360 .0154 \\
\hline $\mathrm{CS}$ & 0.0528 & 0.02840 .0243 & 0.02780 .0250 \\
\hline $\mathrm{AR}(1)$ & 0.2406 & 0.23900 .0016 & 0.22570 .0149 \\
\hline ARMA-r=0.2 & 0.3187 & 0.31760 .0012 & 0.30560 .0132 \\
\hline ARMA-r $=0.45$ & 0.2553 & 0.25380 .0016 & 0.24020 .0151 \\
\hline ARMA-r=0.75 & 0.1785 & 0.17650 .0020 & 0.16280 .0157 \\
\hline \multirow{2}{*}{\multicolumn{2}{|c|}{$\sigma^{2}=2$}} & \multicolumn{2}{|c|}{\begin{tabular}{||c|} 
B \\
\end{tabular}} \\
\hline & & Same structure & Toeplitz \\
\hline$\Sigma$ & \begin{tabular}{|l|}
$L_{\Sigma, A}^{*}$ \\
\end{tabular} & $\begin{array}{|ll|}L_{A, B}^{*} & L_{\Sigma, B}^{*} \\
\end{array}$ & $L_{A, B}^{*} \quad L_{\Sigma, B}^{*}$ \\
\hline $\mathrm{MA}(1)$ & 0.2591 & 0.25850 .0006 & 0.24400 .0151 \\
\hline $\mathrm{CS}$ & 0.0430 & $\begin{array}{|ll|}0.0282 & 0.0148 \\
\end{array}$ & 0.02770 .0153 \\
\hline $\mathrm{AR}(1)$ & 0.2395 & $\begin{array}{|ll|}0.2375 & 0.0020\end{array}$ & 0.22420 .0153 \\
\hline ARMA-r $=0.2$ & 0.3185 & 0.31730 .0012 & 0.30450 .0140 \\
\hline ARMA-r=0.45 & 0.2534 & $\begin{array}{|ll|}0.2512 & 0.0022 \\
\end{array}$ & 0.23860 .0148 \\
\hline ARMA-r=0.75 & 0.1772 & 0.17460 .0026 & 0.16050 .0167 \\
\hline \multirow{2}{*}{\multicolumn{2}{|c|}{$\sigma^{2}=4$}} & \multicolumn{2}{|c|}{\begin{tabular}{|c|} 
\\
$B$
\end{tabular}} \\
\hline & & Same structure & Toeplitz \\
\hline$\Sigma$ & $L_{\Sigma, A}^{*}$ & $L_{A, B}^{*} \quad L_{\Sigma, B}^{*}$ & $L_{A, B}^{*} \quad L_{\Sigma, B}^{*}$ \\
\hline MA(1) & 0.2593 & 0.25870 .0006 & 0.24490 .0144 \\
\hline $\mathrm{CS}$ & 0.0451 & 0.02840 .0167 & 0.02780 .0173 \\
\hline $\mathrm{AR}(1)$ & 0.2426 & $\begin{array}{|ll|}0.2409 & 0.0017 \\
\end{array}$ & 0.22730 .0153 \\
\hline ARMA-r $=0.2$ & 0.3195 & $\begin{array}{|lll|}0.3182 & 0.0013 \\
\end{array}$ & 0.30530 .0142 \\
\hline ARMA-r=0.45 & 0.2544 & 0.25230 .0020 & 0.23920 .0151 \\
\hline ARMA-r=0.75 & 0.1771 & $\mid \begin{array}{lll}0.1744 & 0.0027 \\
\end{array}$ & 0.16070 .0164 \\
\hline
\end{tabular}


Table 3 Simulation results with $m=50 ; c=0.75$.

\begin{tabular}{|c|c|c|c|}
\hline \multirow{2}{*}{\multicolumn{2}{|c|}{$\sigma^{2}=0.50$}} & \multicolumn{2}{|c|}{ B } \\
\hline & & \begin{tabular}{|l|} 
Same structure \\
\end{tabular} & Toeplitz \\
\hline$\Sigma$ & $L_{\Sigma . A}^{*}$ & $\begin{array}{|ll|}L_{A, B}^{*} & L_{\Sigma, B}^{*} \\
\end{array}$ & $L_{A, B}^{*} \quad L_{\Sigma, B}^{*}$ \\
\hline $\mathrm{CS}$ & 0.0393 & $\begin{array}{|ll|}0.0079 & 0.0314 \\
\end{array}$ & 0.00780 .0315 \\
\hline $\mathrm{AR}(1)$ & 0.1356 & 0.13080 .0049 & 0.11860 .0170 \\
\hline ARMA-r $=0.25$ & 0.2887 & $0.2866 \quad 0.0022$ & 0.27510 .0136 \\
\hline ARMA-r=0.5 & 0.1994 & 0.19550 .0039 & 0.18310 .0163 \\
\hline ARMA-r $=0.8$ & 0.1271 & 0.12190 .0051 & 0.10940 .0177 \\
\hline \multirow{2}{*}{\multicolumn{2}{|c|}{$\sigma^{2}=1$}} & \multicolumn{2}{|c|}{ B } \\
\hline & & Same structure & Toeplitz \\
\hline$\Sigma$ & $L_{\Sigma, A}^{*}$ & $\begin{array}{|ll|}L_{A, B}^{*} & L_{\Sigma, B}^{*} \\
\end{array}$ & \begin{tabular}{|ll}
$L_{A, B}^{*}$ & $L_{\Sigma, B}^{*}$ \\
\end{tabular} \\
\hline CS & 0.0263 & $\begin{array}{|lll|}0.0076 & 0.0187\end{array}$ & 0.00750 .0189 \\
\hline $\mathrm{AR}(1)$ & 0.1351 & $\begin{array}{|lll|}0.1302 & 0.0049\end{array}$ & 0.11620 .0189 \\
\hline ARMA-r $=0.25$ & 0.2862 & $\begin{array}{|lll|}0.2836 & 0.0027\end{array}$ & 0.27160 .0146 \\
\hline ARMA-r $=0.5$ & 0.2024 & 0.19880 .0035 & 0.18690 .0155 \\
\hline ARMA-r $=0.8$ & 0.1268 & $\begin{array}{|ll|}0.1220 & 0.0049 \\
\end{array}$ & 0.10890 .0179 \\
\hline \multirow{2}{*}{\multicolumn{2}{|c|}{$\sigma^{2}=2$}} & \multicolumn{2}{|c|}{ B } \\
\hline & & Same structure & Toeplitz \\
\hline \multicolumn{2}{|l|}{$\frac{0}{\Sigma}$} & $\begin{array}{|ll|}L_{A, B}^{*} & L_{\Sigma, B}^{*} \\
\end{array}$ & $\begin{array}{ll}L_{A, B}^{*} & L_{\Sigma, B}^{*}\end{array}$ \\
\hline $\mathrm{CS}$ & 0.0260 & \begin{tabular}{|lll}
0.0077 & 0.0182
\end{tabular} & 0.00760 .0184 \\
\hline $\mathrm{AR}(1)$ & 0.1350 & $\begin{array}{|ll|}0.1303 & 0.0047\end{array}$ & 0.11910 .0159 \\
\hline ARMA-r $=0.25$ & 0.2899 & 0.28790 .0021 & 0.27600 .0139 \\
\hline ARMA-r $=0.5$ & 0.2038 & $0.2004 \quad 0.0034$ & 0.18780 .0160 \\
\hline ARMA-r $=0.8$ & 0.1250 & $\begin{array}{|ll|}0.1201 & 0.0050 \\
\end{array}$ & 0.10770 .0173 \\
\hline \multirow{2}{*}{\multicolumn{2}{|c|}{$\sigma^{2}=4$}} & \multicolumn{2}{|c|}{ B } \\
\hline & & \begin{tabular}{|l|} 
Same structure \\
\end{tabular} & Toeplitz \\
\hline \multicolumn{2}{|l|}{$\Sigma$} & $\begin{array}{|ll|}L_{A, B}^{*} & L_{\Sigma, B}^{*} \\
\end{array}$ & $\begin{array}{ll}L_{A, B}^{*} & L_{\Sigma, B}^{*}\end{array}$ \\
\hline $\mathrm{CS}$ & 0.0301 & $\begin{array}{|ll|}0.0078 & 0.0223 \\
\end{array}$ & 0.00760 .0224 \\
\hline $\mathrm{AR}(1)$ & 0.1334 & 0.12830 .0051 & 0.11680 .0166 \\
\hline ARMA-r $=0.25$ & 0.2888 & 0.28610 .0026 & 0.27380 .0149 \\
\hline ARMA-r $=0.5$ & 0.2028 & $\begin{array}{|ll|}0.1987 & 0.0042\end{array}$ & 0.18740 .0154 \\
\hline ARMA-r $=0.8$ & 0.1251 & $\begin{array}{lll}0.1193 & 0.0059\end{array}$ & 0.10760 .0176 \\
\hline
\end{tabular}


Table 4 Simulation results with $m=100 ; c=0.25$.

\begin{tabular}{|c|c|c|c|}
\hline \multirow{2}{*}{\multicolumn{2}{|c|}{$\sigma^{2}=0.50$}} & \multicolumn{2}{|c|}{ B } \\
\hline & & \begin{tabular}{|l|} 
Same structure \\
\end{tabular} & Toeplitz \\
\hline$\Sigma$ & $L_{\Sigma, A}^{*}$ & $\begin{array}{|ll|}L_{A, B}^{*} & L_{\Sigma, B}^{*} \\
\end{array}$ & $L_{A, B}^{*} \quad L_{\Sigma, B}^{*}$ \\
\hline MA(1) & 0.4758 & $\begin{array}{|ll|}0.4756 & 0.0002\end{array}$ & 0.46540 .0105 \\
\hline CS & 0.1342 & $0.1190 \quad 0.0152$ & 0.11730 .0169 \\
\hline $\mathrm{AR}(1)$ & 0.4748 & $\begin{array}{|ll|}0.4745 & 0.0003 \\
\end{array}$ & 0.46430 .0105 \\
\hline ARMA-r $=0.1$ & 0.4993 & $\begin{array}{|ll|}0.4990 & 0.0003 \\
\end{array}$ & 0.48910 .0102 \\
\hline ARMA-r $=0.35$ & 0.4474 & $\begin{array}{|ll|}0.4469 & 0.0005 \\
\end{array}$ & 0.43660 .0108 \\
\hline ARMA-r=0.6 & 0.3682 & 0.36760 .0006 & 0.35590 .0123 \\
\hline \multirow{2}{*}{\multicolumn{2}{|c|}{$\sigma^{2}=1$}} & \multicolumn{2}{|c|}{$\mathrm{B}$} \\
\hline & & Same structure & Toeplitz \\
\hline \multicolumn{2}{|l|}{$\mid c-1$} & $\begin{array}{|ll|}L_{A, B}^{*} & L_{\Sigma, B}^{*} \\
\end{array}$ & $L_{A, B}^{*} \quad L_{\Sigma, B}^{*}$ \\
\hline $\mathrm{MA}(1)$ & 0.4766 & 0.47640 .0003 & 0.46620 .0105 \\
\hline $\mathrm{CS}$ & 0.1399 & $\begin{array}{|ll|}0.1204 & 0.0195 \\
\end{array}$ & 0.11870 .0212 \\
\hline $\mathrm{AR}(1)$ & 0.4743 & $\begin{array}{|ll|}0.4740 & 0.0003 \\
\end{array}$ & 0.46370 .0106 \\
\hline ARMA-r $=0.1$ & 0.5001 & $\begin{array}{|ll|}0.4998 & 0.0003 \\
\end{array}$ & 0.48990 .0102 \\
\hline ARMA-r=0.35 & 0.4481 & $\begin{array}{|ll|}0.4476 & 0.0005 \\
\end{array}$ & 0.43670 .0113 \\
\hline ARMA-r $=0.6$ & 0.3676 & 0.36700 .0007 & 0.35510 .0125 \\
\hline \multirow{2}{*}{\multicolumn{2}{|c|}{$\sigma^{2}=2$}} & \multicolumn{2}{|c|}{$\mathrm{B}$} \\
\hline & & \multicolumn{2}{|l|}{ Same structure } \\
\hline$\Sigma$ & $L_{\Sigma, A}^{*}$ & $\begin{array}{|ll|}L_{A, B}^{*} & L_{\Sigma, B}^{*} \\
\end{array}$ & $\begin{array}{ll}L_{A, B}^{*} & L_{\Sigma, B}^{*}\end{array}$ \\
\hline $\mathrm{MA}(1)$ & 0.4764 & $\begin{array}{|ll|}0.4762 & 0.0002 \\
\end{array}$ & 0.46580 .0106 \\
\hline $\mathrm{CS}$ & 0.1352 & $\begin{array}{|ll|}0.1174 & 0.0178 \\
\end{array}$ & 0.11570 .0195 \\
\hline $\mathrm{AR}(1)$ & 0.4735 & $\begin{array}{|ll|}0.4731 & 0.0004 \\
\end{array}$ & 0.46230 .0111 \\
\hline ARMA-r $=0.1$ & 0.5003 & $\begin{array}{|ll|}0.5000 & 0.0003\end{array}$ & 0.49020 .0101 \\
\hline ARMA-r=0.35 & 0.4485 & \begin{tabular}{|ll|l|}
0.4480 & 0.0005
\end{tabular} & 0.43730 .0112 \\
\hline ARMA-r=0.6 & 0.3694 & 0.36880 .0006 & 0.35690 .0125 \\
\hline \multirow{2}{*}{\multicolumn{2}{|c|}{$\sigma^{2}=4$}} & \multicolumn{2}{|c|}{ B } \\
\hline & & Same structure & Toeplitz \\
\hline \multicolumn{2}{|l|}{$\Sigma$} & $\begin{array}{|ll|}L_{A, B}^{*} & L_{\Sigma, B}^{*} \\
\end{array}$ & $L_{A, B}^{*} \quad L_{\Sigma, B}^{*}$ \\
\hline MA(1) & 0.4772 & $\begin{array}{|cc|}0.4769 & 0.0002 \\
0.47\end{array}$ & 0.46690 .0103 \\
\hline $\mathrm{CS}$ & 0.1360 & $\begin{array}{|ll|}0.1173 & 0.0187 \\
\end{array}$ & 0.11560 .0204 \\
\hline$\overline{\mathrm{AR}(1)}$ & 0.4753 & $\begin{array}{|lll|}0.4750 & 0.0003\end{array}$ & 0.46490 .0104 \\
\hline ARMA-r $=0.1$ & 0.5004 & 0.50010 .0003 & 0.49030 .0101 \\
\hline ARMA-r $=0.35$ & 0.4480 & 0.44760 .0005 & 0.43740 .0106 \\
\hline ARMA-r=0.6 & 0.3697 & $\begin{array}{|lll|}0.3691 & 0.0005 \\
\end{array}$ & 0.35710 .0125 \\
\hline
\end{tabular}


Table 5 Simulation results with $m=100 ; c=0.5$.

\begin{tabular}{|c|c|c|c|}
\hline \multirow{2}{*}{\multicolumn{2}{|c|}{$\sigma^{2}=0.50$}} & \multicolumn{2}{|c|}{ B } \\
\hline & & \begin{tabular}{|l|} 
Same structure \\
\end{tabular} & Toeplitz \\
\hline$\Sigma$ & $L_{\Sigma . A}^{*}$ & $\begin{array}{|ll|}L_{A, B}^{*} & L_{\Sigma, B}^{*} \\
\end{array}$ & $L_{A, B}^{*} \quad L_{\Sigma, B}^{*}$ \\
\hline $\mathrm{MA}(1)$ & 0.4069 & $\begin{array}{|cc|}A, D & L, D \\
0.4067 & 0.0002\end{array}$ & 0.39490 .0120 \\
\hline CS & 0.0521 & $\begin{array}{lll}0.0296 & 0.0225\end{array}$ & 0.02930 .0229 \\
\hline $\mathrm{AR}(1)$ & 0.3832 & $\begin{array}{|ll|}0.3825 & 0.0007 \\
\end{array}$ & 0.37110 .0121 \\
\hline ARMA-r $=0.2$ & 0.4793 & 0.47890 .0004 & 0.46880 .0105 \\
\hline ARMA-r $=0.45$ & 0.4000 & 0.39930 .0008 & 0.38820 .0118 \\
\hline ARMA-r=0.75 & 0.2945 & $\begin{array}{|ll|}0.2936 & 0.0009 \\
\end{array}$ & 0.28080 .0136 \\
\hline \multirow{2}{*}{\multicolumn{2}{|c|}{$\sigma^{2}=1$}} & \multicolumn{2}{|c|}{$\mathrm{B}$} \\
\hline & & Same structure & Toeplitz \\
\hline \multicolumn{2}{|l|}{$\mid c-1$} & $\begin{array}{|ll|}L_{A, B}^{*} & L_{\Sigma, B}^{*} \\
\end{array}$ & $L_{A, B}^{*} \quad L_{\Sigma, B}^{*}$ \\
\hline $\mathrm{MA}(1)$ & 0.4074 & $\begin{array}{|lll|}0.4072 & 0.0002\end{array}$ & 0.39600 .0114 \\
\hline $\mathrm{CS}$ & 0.0459 & $\begin{array}{|ll|}0.0297 & 0.0162 \\
\end{array}$ & 0.02930 .0165 \\
\hline $\mathrm{AR}(1)$ & 0.3825 & $\begin{array}{|ll|}0.3817 & 0.0007 \\
\end{array}$ & 0.36980 .0127 \\
\hline ARMA-r $=0.2$ & 0.4810 & $\begin{array}{|ll|}0.4805 & 0.0005 \\
\end{array}$ & 0.47050 .0105 \\
\hline ARMA-r=0.45 & 0.4003 & $\begin{array}{|ll|}0.3997 & 0.0006 \\
\end{array}$ & 0.38780 .0125 \\
\hline ARMA-r $=0.75$ & 0.2956 & \begin{tabular}{lll|}
0.2945 & 0.0011 \\
\end{tabular} & 0.28140 .0141 \\
\hline \multirow{2}{*}{\multicolumn{2}{|c|}{$\sigma^{2}=2$}} & \multicolumn{2}{|c|}{$\mathrm{B}$} \\
\hline & & Same structure & Toeplitz \\
\hline$\Sigma$ & $L_{\Sigma, A}^{*}$ & $\begin{array}{|ll|}L_{A, B}^{*} & L_{\Sigma, B}^{*} \\
\end{array}$ & $\begin{array}{ll}L_{A, B}^{*} & L_{\Sigma, B}^{*}\end{array}$ \\
\hline $\mathrm{MA}(1)$ & 0.4067 & $\begin{array}{|lll|}0.4064 & 0.0002 \\
\end{array}$ & 0.39420 .0125 \\
\hline $\mathrm{CS}$ & 0.0512 & $\begin{array}{|ll|}0.0291 & 0.0221 \\
\end{array}$ & 0.02880 .0224 \\
\hline $\mathrm{AR}(1)$ & 0.3822 & $\begin{array}{|ll|}0.3816 & 0.0006 \\
\end{array}$ & 0.36990 .0123 \\
\hline ARMA-r $=0.2$ & 0.4804 & $\begin{array}{|ll|}0.4799 & 0.0005\end{array}$ & 0.46990 .0105 \\
\hline ARMA-r=0.45 & 0.4006 & $\begin{array}{|lll|}0.4000 & 0.0007\end{array}$ & 0.38870 .0120 \\
\hline ARMA-r=0.75 & 0.2937 & 0.29280 .0009 & 0.27970 .0139 \\
\hline \multirow{2}{*}{\multicolumn{2}{|c|}{$\sigma^{2}=4$}} & \multicolumn{2}{|c|}{ B } \\
\hline & & Same structure & Toeplitz \\
\hline$\Sigma$ & $L_{\Sigma, A}^{*}$ & $\begin{array}{|ll|}L_{A, B}^{*} & L_{\Sigma, B}^{*} \\
\end{array}$ & $L_{A, B}^{*} \quad L_{\Sigma, B}^{*}$ \\
\hline $\mathrm{MA}(1)$ & 0.4062 & $\begin{array}{|cc|}0.4059 & 0.0003 \\
\end{array}$ & 0.39460 .0116 \\
\hline $\mathrm{CS}$ & 0.0512 & 0.02840 .0228 & 0.02810 .0231 \\
\hline$\overline{\mathrm{AR}(1)}$ & 0.3823 & \begin{tabular}{|ll|l|}
0.3818 & 0.0005
\end{tabular} & 0.37010 .0122 \\
\hline ARMA-r $=0.2$ & 0.4803 & 0.47980 .0005 & 0.46950 .0108 \\
\hline ARMA-r=0.45 & 0.4011 & 0.40020 .0009 & 0.38840 .0126 \\
\hline ARMA-r=0.75 & 0.2928 & $\begin{array}{|lll|}0.2919 & 0.0009 \\
\end{array}$ & 0.27920 .0136 \\
\hline
\end{tabular}


Table 6 Simulation results with $m=100 ; c=0.75$.

\begin{tabular}{|c|c|c|c|}
\hline \multirow{2}{*}{\multicolumn{2}{|c|}{$\sigma^{2}=0.50$}} & \multicolumn{2}{|c|}{ B } \\
\hline & & \begin{tabular}{|l|} 
Same structure \\
\end{tabular} & Toeplitz \\
\hline$\Sigma$ & $L_{\Sigma, A}^{*}$ & $\begin{array}{|ll|}L_{A, B}^{*} & L_{\Sigma, B}^{*} \\
\end{array}$ & $L_{A, B}^{*} \quad L_{\Sigma, B}^{*}$ \\
\hline $\mathrm{CS}$ & 0.0265 & $\begin{array}{|lll|}0.0076 & 0.0190\end{array}$ & 0.00750 .0190 \\
\hline $\mathrm{AR}(1)$ & 0.2307 & \begin{tabular}{|lll}
0.2289 & 0.0018
\end{tabular} & 0.21640 .0143 \\
\hline ARMA-r $=0.25$ & 0.4444 & $\begin{array}{|lll|}0.4436 & 0.0008 \\
\end{array}$ & 0.43370 .0107 \\
\hline ARMA-r $=0.5$ & 0.3265 & $\begin{array}{|ll|}0.3249 & 0.0016 \\
\end{array}$ & 0.31360 .0128 \\
\hline ARMA-r $=0.8$ & 0.2139 & $\begin{array}{|ll|}0.2119 & 0.0020 \\
\end{array}$ & 0.19900 .0149 \\
\hline \multirow{2}{*}{\multicolumn{2}{|c|}{$\sigma^{2}=1$}} & \multicolumn{2}{|l|}{ B } \\
\hline & & Same structure & Toeplitz \\
\hline$\Sigma$ & $L_{\Sigma, A}^{*}$ & $\begin{array}{ll}L_{A, B}^{*} & L_{\Sigma, B}^{*} \\
\end{array}$ & $\begin{array}{ll}L_{A, B}^{*} & L_{\Sigma, B}^{*}\end{array}$ \\
\hline $\mathrm{CS}$ & 0.0275 & \begin{tabular}{|lll}
0.0078 & 0.0197
\end{tabular} & 0.00780 .0198 \\
\hline $\mathrm{AR}(1)$ & 0.2315 & $\begin{array}{|lll|}0.2294 & 0.0021\end{array}$ & \begin{tabular}{|l|l|}
0.2176 & 0.0139 \\
\end{tabular} \\
\hline ARMA-r $=0.25$ & 0.4445 & \begin{tabular}{|lll}
0.4436 & 0.0009 \\
\end{tabular} & 0.43350 .0110 \\
\hline ARMA-r $=0.5$ & 0.3275 & 0.32590 .0016 & \begin{tabular}{|lll}
0.3139 & 0.0136
\end{tabular} \\
\hline ARMA-r $=0.8$ & 0.2137 & $0.2115 \quad 0.0022$ & 0.19860 .0150 \\
\hline \multirow{2}{*}{\multicolumn{2}{|c|}{$\sigma^{2}=2$}} & \multicolumn{2}{|c|}{ B } \\
\hline & & Same structure & Toeplitz \\
\hline$\Sigma$ & $L_{\Sigma, A}^{*}$ & $\begin{array}{|ll|}L_{A, B}^{*} & L_{\Sigma, B}^{*} \\
\end{array}$ & $\begin{array}{ll}L_{A, B}^{*} & L_{\Sigma, B}^{*} \\
\end{array}$ \\
\hline $\mathrm{CS}$ & 0.0384 & $\begin{array}{|lll|}0.0079 & 0.0305 \\
\end{array}$ & 0.00780 .0306 \\
\hline $\mathrm{AR}(1)$ & 0.2294 & $\begin{array}{|ll|}0.2271 & 0.0023 \\
\end{array}$ & 0.21380 .0156 \\
\hline ARMA-r $=0.25$ & 0.4439 & $\begin{array}{|lll|}0.4428 & 0.0011\end{array}$ & 0.43240 .0115 \\
\hline ARMA-r $=0.5$ & 0.3253 & 0.32350 .0018 & 0.31230 .0130 \\
\hline ARMA-r $=0.8$ & 0.2151 & 0.21290 .0022 & 0.20020 .0149 \\
\hline \multirow{2}{*}{\multicolumn{2}{|c|}{$\sigma^{2}=4$}} & \multicolumn{2}{|c|}{\begin{tabular}{|c|}
$\mathrm{B}$ \\
\end{tabular}} \\
\hline & & Same structure & Toeplitz \\
\hline$\Sigma$ & $L_{\Sigma, A}^{*}$ & $\begin{array}{ll}L_{A, B}^{*} & L_{\Sigma, B}^{*} \\
\end{array}$ & $\begin{array}{ll}L_{A, B}^{*} & L_{\Sigma, B}^{*} \\
\end{array}$ \\
\hline CS & 0.0423 & 0.00800 .0343 & 0.00790 .0344 \\
\hline $\mathrm{AR}(1)$ & 0.2291 & $\begin{array}{lll}0.2271 & 0.0020\end{array}$ & 0.21340 .0157 \\
\hline ARMA-r $=0.25$ & 0.4432 & $\begin{array}{|ll|}0.4421 & 0.0011 \\
\end{array}$ & 0.43200 .0112 \\
\hline ARMA-r $=0.5$ & 0.3264 & $0.3248 \quad 0.0016$ & 0.31310 .0133 \\
\hline ARMA-r $=0.8$ & 0.2142 & 0.21240 .0018 & 0.19910 .0151 \\
\hline
\end{tabular}


Table 7 Simulation results with $m=500 ; c=0.25$.

\begin{tabular}{|c|c|c|c|}
\hline \multirow{2}{*}{\multicolumn{2}{|c|}{$\sigma^{2}=0.50$}} & \multicolumn{2}{|c|}{ B } \\
\hline & & \begin{tabular}{|l|} 
Same structure \\
\end{tabular} & Toeplitz \\
\hline$\Sigma$ & $L_{\Sigma, A}^{*}$ & $\begin{array}{|ll|}L_{A, B}^{*} & L_{\Sigma, B}^{*} \\
\end{array}$ & $L_{A, B}^{*} \quad L_{\Sigma, B}^{*}$ \\
\hline MA(1) & 0.8183 & $\begin{array}{|lll|}0.8183 & 0.0000\end{array}$ & 0.81470 .0036 \\
\hline $\mathrm{CS}$ & 0.1483 & 0.13170 .0166 & 0.13130 .0170 \\
\hline $\mathrm{AR}(1)$ & 0.8169 & $\begin{array}{|ll|}0.8169 & 0.0000 \\
\end{array}$ & 0.81320 .0037 \\
\hline ARMA-r $=0.1$ & 0.8321 & $\begin{array}{lll}0.8321 & 0.0000 \\
\end{array}$ & 0.82870 .0034 \\
\hline ARMA-r $=0.35$ & 0.8006 & 0.80050 .0000 & 0.79650 .0040 \\
\hline ARMA-r $=0.6$ & 0.7414 & $\begin{array}{|ll|}0.7413 & 0.0000 \\
\end{array}$ & 0.73610 .0053 \\
\hline \multirow{2}{*}{\multicolumn{2}{|c|}{$\sigma^{2}=1$}} & \multicolumn{2}{|c|}{$\mathrm{B}$} \\
\hline & & Same structure & Toeplitz \\
\hline$\Sigma$ & $L_{\Sigma, A}^{*}$ & $\begin{array}{|ll|}L_{A, B}^{*} & L_{\Sigma, B}^{*} \\
\end{array}$ & $L_{A, B}^{*} \quad L_{\Sigma, B}^{*}$ \\
\hline $\mathrm{MA}(1)$ & 0.8182 & $\begin{array}{|ll|}0.8181 & 0.0000\end{array}$ & 0.81450 .0037 \\
\hline $\mathrm{CS}$ & 0.1503 & $\begin{array}{|ll|}0.1310 & 0.0193 \\
\end{array}$ & 0.13060 .0197 \\
\hline $\mathrm{AR}(1)$ & 0.8170 & $\begin{array}{|ll|}0.8170 & 0.0000 \\
\end{array}$ & 0.81340 .0037 \\
\hline ARMA-r $=0.1$ & 0.8321 & $\begin{array}{|ll|}0.8321 & 0.0000 \\
\end{array}$ & 0.82870 .0034 \\
\hline ARMA-r $=0.35$ & 0.8007 & $\begin{array}{|ll|}0.8007 & 0.0000 \\
\end{array}$ & 0.79670 .0040 \\
\hline ARMA-r $=0.6$ & 0.7417 & 0.74160 .0000 & 0.73640 .0052 \\
\hline \multirow{2}{*}{\multicolumn{2}{|c|}{$\sigma^{2}=2$}} & \multicolumn{2}{|c|}{\begin{tabular}{|c|}
$\mathrm{B}$ \\
\end{tabular}} \\
\hline & & \begin{tabular}{|l|} 
Same structure \\
\end{tabular} & Toeplitz \\
\hline$\Sigma$ & $L_{\Sigma, A}^{*}$ & $\begin{array}{|ll|}L_{A, B}^{*} & L_{\Sigma, B}^{*} \\
\end{array}$ & $\begin{array}{ll}L_{A, B}^{*} & L_{\Sigma, B}^{*}\end{array}$ \\
\hline MA(1) & 0.8182 & 0.81820 .0000 & 0.81460 .0037 \\
\hline $\mathrm{CS}$ & 0.1511 & $\begin{array}{|lll|}0.1322 & 0.0189\end{array}$ & 0.13180 .0193 \\
\hline $\mathrm{AR}(1)$ & 0.8169 & $\begin{array}{|ll|}0.8169 & 0.0000 \\
\end{array}$ & 0.81320 .0037 \\
\hline ARMA-r $=0.1$ & 0.8319 & $\begin{array}{|ll|}0.8319 & 0.0000\end{array}$ & 0.82850 .0034 \\
\hline ARMA-r $=0.35$ & 0.8009 & 0.80080 .0000 & 0.79690 .0040 \\
\hline ARMA-r $=0.6$ & 0.7418 & 0.74180 .0001 & 0.73660 .0053 \\
\hline \multirow{2}{*}{\multicolumn{2}{|c|}{$\sigma^{2}=4$}} & \multicolumn{2}{|c|}{ B } \\
\hline & & Same structure & Toeplitz \\
\hline$\Sigma$ & $L_{\Sigma, A}^{*}$ & $\begin{array}{|ll|}L_{A, B}^{*} & L_{\Sigma, B}^{*} \\
\end{array}$ & $L_{A, B}^{*} \quad L_{\Sigma, B}^{*}$ \\
\hline MA(1) & 0.8181 & $\begin{array}{llll}0.8180 & 0.0000 \\
\end{array}$ & $0.8144 \quad 0.0037$ \\
\hline $\mathrm{CS}$ & 0.1499 & $\begin{array}{|lll|}0.1321 & 0.0178 \\
\end{array}$ & 0.13170 .0182 \\
\hline $\mathrm{AR}(1)$ & 0.8171 & \begin{tabular}{|ll|l|}
0.8171 & 0.0000
\end{tabular} & 0.81340 .0036 \\
\hline ARMA-r $=0.1$ & 0.8321 & $\begin{array}{lll}0.8321 & 0.0000 \\
\end{array}$ & 0.82870 .0034 \\
\hline ARMA-r $=0.35$ & 0.8007 & 0.80070 .0000 & 0.79670 .0040 \\
\hline ARMA-r $=0.6$ & 0.7412 & 0.74120 .0000 & 0.73610 .0051 \\
\hline
\end{tabular}


Table 8 Simulation results with $m=500 ; c=0.5$.

\begin{tabular}{|c|c|c|c|}
\hline \multirow{2}{*}{\multicolumn{2}{|c|}{$\sigma^{2}=0.50$}} & \multicolumn{2}{|c|}{ B } \\
\hline & & \begin{tabular}{|l|} 
Same structure \\
\end{tabular} & Toeplitz \\
\hline$\Sigma$ & $L_{\Sigma . A}^{*}$ & $\begin{array}{|ll|}L_{A, B}^{*} & L_{\Sigma, B}^{*} \\
\end{array}$ & $L_{A, B}^{*} \quad L_{\Sigma, B}^{*}$ \\
\hline MA(1) & 0.7716 & 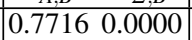 & 0.76700 .0047 \\
\hline CS & 0.0493 & $\begin{array}{llll}0.0307 & 0.0186\end{array}$ & 0.03060 .0187 \\
\hline $\mathrm{AR}(1)$ & 0.7527 & $\begin{array}{|lll|}0.7526 & 0.0001 \\
\end{array}$ & 0.74760 .0050 \\
\hline ARMA-r $=0.2$ & 0.8206 & 0.82060 .0000 & 0.81700 .0036 \\
\hline ARMA-r $=0.45$ & 0.7669 & 0.76680 .0001 & 0.76220 .0046 \\
\hline ARMA-r=0.75 & 0.6702 & $\begin{array}{|ll|}0.6701 & 0.0001 \\
\end{array}$ & 0.66370 .0065 \\
\hline \multirow{2}{*}{\multicolumn{2}{|c|}{$\sigma^{2}=1$}} & \multicolumn{2}{|c|}{$\mathrm{B}$} \\
\hline & & Same structure & Toeplitz \\
\hline \multicolumn{2}{|l|}{$\mid c-1$} & $\begin{array}{|ll|}L_{A, B}^{*} & L_{\Sigma, B}^{*} \\
\end{array}$ & $L_{A, B}^{*} \quad L_{\Sigma, B}^{*}$ \\
\hline $\mathrm{MA}(1)$ & 0.7719 & $\begin{array}{|lll|}0.7719 & 0.0000\end{array}$ & 0.76740 .0046 \\
\hline $\mathrm{CS}$ & 0.0596 & $\begin{array}{|ll|}0.0303 & 0.0293 \\
\end{array}$ & 0.03020 .0294 \\
\hline $\mathrm{AR}(1)$ & 0.7523 & $\begin{array}{|ll|}0.7523 & 0.0000 \\
\end{array}$ & 0.74730 .0050 \\
\hline ARMA-r $=0.2$ & 0.8208 & $\begin{array}{|ll|}0.8208 & 0.0000 \\
\end{array}$ & 0.81720 .0036 \\
\hline ARMA-r=0.45 & 0.7673 & $\begin{array}{|ll|}0.7672 & 0.0001 \\
\end{array}$ & 0.76260 .0047 \\
\hline ARMA-r $=0.75$ & 0.6699 & 0.66990 .0001 & 0.66330 .0067 \\
\hline \multirow{2}{*}{\multicolumn{2}{|c|}{$\sigma^{2}=2$}} & \multicolumn{2}{|c|}{$\mathrm{B}$} \\
\hline & & \begin{tabular}{|l|} 
Same structure \\
\end{tabular} & Toeplitz \\
\hline$\Sigma$ & $L_{\Sigma, A}^{*}$ & $\begin{array}{|ll|}L_{A, B}^{*} & L_{\Sigma, B}^{*} \\
\end{array}$ & $\begin{array}{ll}L_{A, B}^{*} & L_{\Sigma, B}^{*}\end{array}$ \\
\hline $\mathrm{MA}(1)$ & 0.7716 & $\begin{array}{|ll|}0.7715 & 0.0000\end{array}$ & 0.76700 .0045 \\
\hline $\mathrm{CS}$ & 0.0543 & $\begin{array}{|lll|}0.0306 & 0.0237 \\
\end{array}$ & 0.03050 .0238 \\
\hline $\mathrm{AR}(1)$ & 0.7530 & $\begin{array}{|ll|}0.7529 & 0.0001 \\
\end{array}$ & 0.74800 .0050 \\
\hline ARMA-r $=0.2$ & 0.8204 & $\begin{array}{|ll|}0.8204 & 0.0000\end{array}$ & 0.81680 .0036 \\
\hline ARMA-r=0.45 & 0.7671 & $\begin{array}{|lll|}0.7670 & 0.0000\end{array}$ & 0.76240 .0047 \\
\hline ARMA-r=0.75 & 0.6705 & 0.67040 .0001 & 0.66390 .0066 \\
\hline \multirow{2}{*}{\multicolumn{2}{|c|}{$\sigma^{2}=4$}} & \multicolumn{2}{|c|}{ B } \\
\hline & & Same structure & Toeplitz \\
\hline$\Sigma$ & $L_{\Sigma, A}^{*}$ & $\begin{array}{|ll|}L_{A, B}^{*} & L_{\Sigma, B}^{*} \\
\end{array}$ & $L_{A, B}^{*} \quad L_{\Sigma, B}^{*}$ \\
\hline $\mathrm{MA}(1)$ & 0.7717 & $\begin{array}{|cc|}0.7717 & 0.0000 \\
\end{array}$ & 0.76710 .0045 \\
\hline $\mathrm{CS}$ & 0.0547 & $\begin{array}{|lll|}0.0304 & 0.0244 \\
\end{array}$ & 0.03030 .0244 \\
\hline$\overline{\mathrm{AR}(1)}$ & 0.7529 & $\begin{array}{|ll|}0.7529 & 0.0001\end{array}$ & 0.74790 .0050 \\
\hline ARMA-r $=0.2$ & 0.8208 & 0.82070 .0000 & 0.81710 .0036 \\
\hline ARMA-r=0.45 & 0.7669 & 0.76690 .0000 & 0.76230 .0047 \\
\hline ARMA-r $=0.75$ & 0.6701 & $\begin{array}{|lll|}0.6700 & 0.0001 \\
\end{array}$ & 0.66350 .0066 \\
\hline
\end{tabular}


Table 9 Simulation results with $m=500 ; c=0.75$.

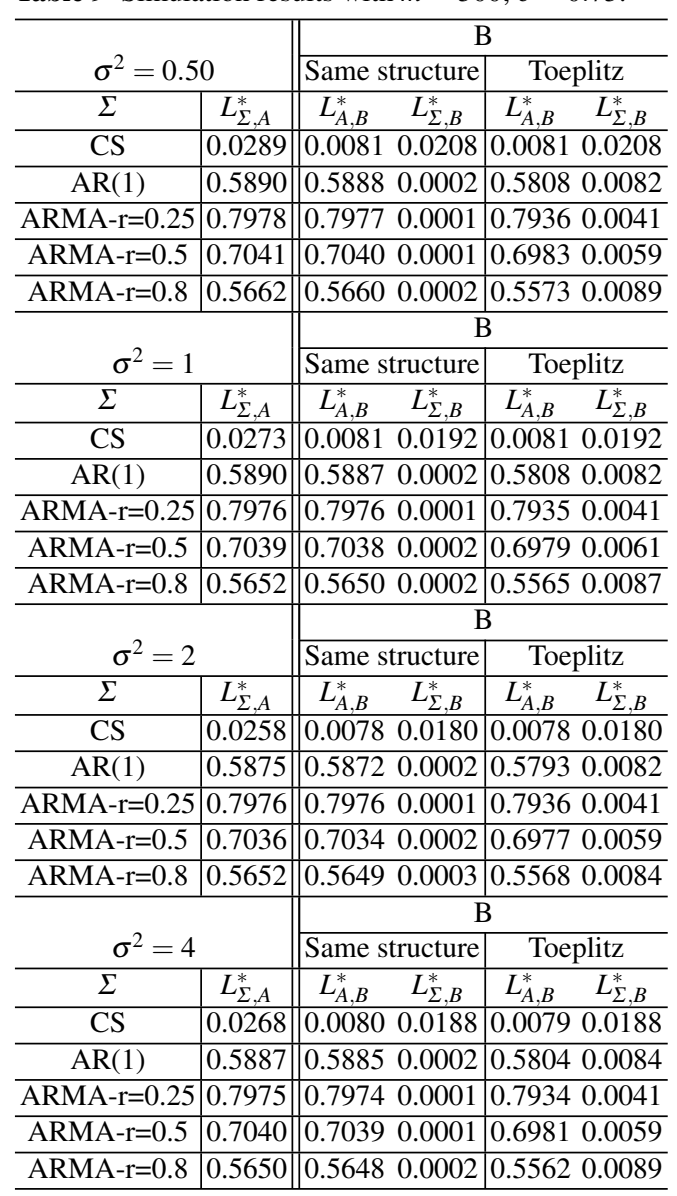


Table 10 Simulation results with $m=1000 ; c=0.25$.

\begin{tabular}{|c|c|c|c|}
\hline \multirow{2}{*}{\multicolumn{2}{|c|}{$\sigma^{2}=0.50$}} & \multicolumn{2}{|c|}{ B } \\
\hline & & Same structure & Toeplitz \\
\hline$\Sigma$ & $L_{\Sigma, A}^{*}$ & $\begin{array}{|ll|}L_{A, B}^{*} & L_{\Sigma, B}^{*} \\
\end{array}$ & $\begin{array}{ll}L_{A, B}^{*} & L_{\Sigma, B}^{*}\end{array}$ \\
\hline MA(1) & 0.8999 & \begin{tabular}{|lll}
0.8999 & 0.0000 \\
\end{tabular} & 0.89790 .0020 \\
\hline $\mathrm{CS}$ & 0.1571 & \begin{tabular}{|lll}
0.1368 & 0.0203
\end{tabular} & 0.13660 .0205 \\
\hline $\mathrm{AR}(1)$ & 0.8992 & $\begin{array}{|ll|}0.8992 & 0.0000 \\
\end{array}$ & \begin{tabular}{|lll}
0.8972 & 0.0020
\end{tabular} \\
\hline ARMA-r $=0.1$ & 0.9082 & $\begin{array}{|ll|}0.9082 & 0.0000 \\
\end{array}$ & $\begin{array}{llll}0.9064 & 0.0018\end{array}$ \\
\hline ARMA-r $=0.35$ & 0.8891 & $\begin{array}{|ll|}0.8891 & 0.0000 \\
\end{array}$ & 0.88690 .0022 \\
\hline ARMA-r $=0.6$ & 0.8512 & 0.85120 .0000 & 0.84820 .0030 \\
\hline \multirow{2}{*}{\multicolumn{2}{|c|}{$\sigma^{2}=1$}} & \multicolumn{2}{|c|}{$\mathrm{B}$} \\
\hline & & Same structure & Toeplitz \\
\hline$\Sigma$ & $L_{\Sigma, A}^{*}$ & $\begin{array}{|ll|}L_{A, B}^{*} & L_{\Sigma, B}^{*} \\
\end{array}$ & $\begin{array}{ll}L_{A, B}^{*} & L_{\Sigma, B}^{*}\end{array}$ \\
\hline MA(1) & 0.8999 & \begin{tabular}{|lll}
0.8999 & 0.0000 \\
\end{tabular} & 0.89790 .0020 \\
\hline $\mathrm{CS}$ & 0.1388 & $\begin{array}{|ll|}0.1268 & 0.0120 \\
\end{array}$ & \begin{tabular}{|l|l|}
0.1266 & 0.0121 \\
\end{tabular} \\
\hline $\mathrm{AR}(1)$ & $\mid 0.8992$ & \begin{tabular}{|lll}
0.8992 & 0.0000
\end{tabular} & 0.89720 .0020 \\
\hline ARMA-r $=0.1$ & 0.9083 & $\begin{array}{|lll|}0.9083 & 0.0000 \\
\end{array}$ & 0.90640 .0019 \\
\hline ARMA-r=0.35 & 0.8893 & $\begin{array}{|ll|}0.8893 & 0.0000 \\
\end{array}$ & 0.88700 .0023 \\
\hline ARMA-r=0.6 & 0.8515 & 0.85150 .0000 & 0.84850 .0030 \\
\hline \multirow{2}{*}{\multicolumn{2}{|c|}{$\sigma^{2}=2$}} & \multicolumn{2}{|c|}{\begin{tabular}{|c|}
$\mathrm{B}$ \\
\end{tabular}} \\
\hline & & Same structure & Toeplitz \\
\hline$\Sigma$ & $L_{\Sigma . A}^{*}$ & $\begin{array}{ll}L_{A, B}^{*} & L_{\Sigma, B}^{*} \\
\end{array}$ & $\begin{array}{ll}L_{A, B}^{*} & L_{\Sigma, B}^{*}\end{array}$ \\
\hline $\mathrm{MA}(1)$ & 0.8999 & $\begin{array}{|ll|}0.8999 & 0.0000\end{array}$ & 0.89790 .0020 \\
\hline $\mathrm{CS}$ & 0.1517 & $\begin{array}{|ll|}0.1347 & 0.0170 \\
\end{array}$ & 0.13450 .0172 \\
\hline $\mathrm{AR}(1)$ & 0.8993 & $\begin{array}{|ll|}0.8993 & 0.0000 \\
\end{array}$ & 0.89730 .0020 \\
\hline ARMA-r $=0.1$ & 0.9083 & $\begin{array}{|ll|}0.9083 & 0.0000 \\
\end{array}$ & 0.90640 .0019 \\
\hline ARMA-r=0.35 & 0.8892 & $\begin{array}{|ll|}0.8892 & 0.0000 \\
\end{array}$ & 0.88700 .0022 \\
\hline ARMA-r=0.6 & 0.8513 & 0.85130 .0000 & 0.84830 .0030 \\
\hline \multirow{2}{*}{\multicolumn{2}{|c|}{$\sigma^{2}=4$}} & \multicolumn{2}{|c|}{ B } \\
\hline & & Same structure & Toeplitz \\
\hline \multicolumn{2}{|l|}{\begin{tabular}{|l|}
$\Sigma$ \\
\end{tabular}} & $\begin{array}{ll}L_{A, B}^{*} & L_{\Sigma, B}^{*} \\
\end{array}$ & $\begin{array}{ll}L_{A, B}^{*} & L_{\Sigma, B}^{*} \\
\end{array}$ \\
\hline MA(1) & 0.8999 & 0.89990 .0000 & 0.89790 .0020 \\
\hline $\mathrm{CS}$ & 0.1388 & $\begin{array}{|ll|}0.1268 & 0.0120\end{array}$ & 0.12660 .0121 \\
\hline $\mathrm{AR}(1)$ & 0.8992 & $\begin{array}{|ll|}0.8992 & 0.0000 \\
\end{array}$ & 0.89720 .0020 \\
\hline ARMA-r $=0.1$ & 0.9083 & $\begin{array}{|ll|}0.9083 & 0.0000\end{array}$ & 0.90640 .0019 \\
\hline ARMA-r $=0.35$ & 0.8893 & \begin{tabular}{|lll}
0.8893 & 0.0000
\end{tabular} & 0.88700 .0023 \\
\hline ARMA-r=0.6 & 0.8515 & $\begin{array}{llll}0.8515 & 0.0000\end{array}$ & 0.84850 .0030 \\
\hline
\end{tabular}


Table 11 Simulation results with $m=1000 ; c=0.5$.

\begin{tabular}{|c|c|c|c|}
\hline \multirow{2}{*}{\multicolumn{2}{|c|}{$\sigma^{2}=0.50$}} & \multicolumn{2}{|c|}{ B } \\
\hline & & Same structure & Toeplitz \\
\hline$\Sigma$ & $L_{\Sigma, A}^{*}$ & 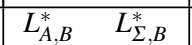 & $L_{A, B}^{*} \quad L_{\Sigma, B}^{*}$ \\
\hline MA(1) & 0.8709 & $\begin{array}{|ll|}0.8709 & 0.0000 \\
\end{array}$ & 0.86830 .0026 \\
\hline $\mathrm{CS}$ & 0.0525 & $\begin{array}{|ll|}0.0308 & 0.0217 \\
\end{array}$ & 0.03080 .0217 \\
\hline $\mathrm{AR}(1)$ & 0.8587 & $\begin{array}{|lll|}0.8586 & 0.0000 \\
\end{array}$ & 0.85580 .0028 \\
\hline ARMA-r $=0.2$ & 0.9014 & $\begin{array}{|lll|}0.9014 & 0.0000 \\
\end{array}$ & 0.89940 .0020 \\
\hline ARMA-r $=0.45$ & 0.8678 & $\begin{array}{lll}0.8678 & 0.0000\end{array}$ & $\begin{array}{lll}0.8651 & 0.0027\end{array}$ \\
\hline ARMA-r $=0.75$ & 0.8022 & $\begin{array}{|lll|}0.8022 & 0.0000 \\
\end{array}$ & 0.79830 .0039 \\
\hline \multirow{2}{*}{\multicolumn{2}{|c|}{$\sigma^{2}=1$}} & \multicolumn{2}{|c|}{$\mathrm{B}$} \\
\hline & & Same structure & Toeplitz \\
\hline$\Sigma$ & $L_{\Sigma, A}^{*}$ & $\begin{array}{|ll|}L_{A, B}^{*} & L_{\Sigma, B}^{*} \\
\end{array}$ & $\begin{array}{ll}L_{A, B}^{*} & L_{\Sigma, B}^{*} \\
\end{array}$ \\
\hline MA(1) & 0.8709 & $\begin{array}{llll}0.8709 & 0.0000 \\
\end{array}$ & 0.86830 .0026 \\
\hline $\mathrm{CS}$ & 0.0550 & $\begin{array}{|lll|}0.0306 & 0.0244\end{array}$ & 0.03060 .0245 \\
\hline $\mathrm{AR}(1)$ & 0.8586 & $\begin{array}{|lll|}0.8586 & 0.0000\end{array}$ & 0.85580 .0029 \\
\hline ARMA-r $=0.2$ & 0.9014 & $\begin{array}{llll}0.9014 & 0.0000\end{array}$ & 0.89940 .0020 \\
\hline ARMA-r $=0.45$ & 0.8680 & $\begin{array}{llll}0.8680 & 0.0000 \\
\end{array}$ & 0.86540 .0026 \\
\hline ARMA-r=0.75 & 0.8020 & 0.80200 .0000 & 0.79800 .0040 \\
\hline \multirow{2}{*}{\multicolumn{2}{|c|}{$\sigma^{2}=2$}} & \multicolumn{2}{|l|}{ B } \\
\hline & & Same structure & Toeplitz \\
\hline$\Sigma$ & $L_{\Sigma, A}^{*}$ & $\begin{array}{|ll|}L_{A, B}^{*} & L_{\Sigma, B}^{*} \\
\end{array}$ & $\begin{array}{ll}L_{A, B}^{*} & L_{\Sigma, B}^{*}\end{array}$ \\
\hline $\mathrm{MA}(1)$ & 0.8709 & $\begin{array}{|lll|}0.8709 & 0.0000 \\
\end{array}$ & 0.86830 .0026 \\
\hline $\mathrm{CS}$ & 0.0525 & $\begin{array}{|ll|}0.0302 & 0.0223 \\
\end{array}$ & 0.03010 .0224 \\
\hline $\mathrm{AR}(1)$ & 0.8586 & $\begin{array}{llll}0.8586 & 0.0000 \\
\end{array}$ & 0.85570 .0029 \\
\hline ARMA-r $=0.2$ & 0.9013 & $\begin{array}{|lll|}0.9013 & 0.0000 \\
\end{array}$ & 0.89930 .0020 \\
\hline ARMA-r $=0.45$ & 0.8678 & $\begin{array}{llll}0.8678 & 0.0000 \\
\end{array}$ & 0.86520 .0026 \\
\hline ARMA-r=0.75 & 0.8018 & $\begin{array}{|lll|}0.8018 & 0.0000\end{array}$ & 0.79780 .0040 \\
\hline \multirow{2}{*}{\multicolumn{2}{|c|}{$\sigma^{2}=4$}} & \multicolumn{2}{|c|}{\begin{tabular}{|c|} 
B \\
\end{tabular}} \\
\hline & & Same structure & Toeplitz \\
\hline \multicolumn{2}{|l|}{$\Sigma$} & $\begin{array}{|ll|}L_{A, B}^{*} & L_{\Sigma, B}^{*} \\
\end{array}$ & $L_{A, B}^{*} \quad L_{\Sigma, B}^{*}$ \\
\hline MA(1) & 0.8709 & $\begin{array}{|lll|}0.8709 & 0.0000 \\
\end{array}$ & 0.86830 .0026 \\
\hline $\mathrm{CS}$ & 0.0555 & 0.03090 .0245 & 0.03090 .0245 \\
\hline $\operatorname{AR}(1)$ & 0.8585 & 0.85850 .0000 & 0.85570 .0028 \\
\hline ARMA-r $=0.2$ & 0.9013 & 0.90130 .0000 & 0.89930 .0020 \\
\hline ARMA-r=0.45 & 0.8679 & 0.86790 .0000 & 0.86520 .0027 \\
\hline ARMA-r=0.75 & 0.8021 & $\begin{array}{llll}0.8020 & 0.0000 \\
\end{array}$ & 0.79810 .0040 \\
\hline
\end{tabular}


Table 12 Simulation results with $m=1000 ; c=0.75$.

\begin{tabular}{|c|c|c|c|}
\hline \multirow{2}{*}{\multicolumn{2}{|c|}{$\sigma^{2}=0.50$}} & \multicolumn{2}{|c|}{ B } \\
\hline & & Same structure & Toeplitz \\
\hline$\Sigma$ & $L_{\Sigma, A}^{*}$ & $\begin{array}{|ll|}L_{A, B}^{*} & L_{\Sigma, B}^{*} \\
\end{array}$ & $\begin{array}{ll}L_{A, B}^{*} & L_{\Sigma, B}^{*}\end{array}$ \\
\hline $\mathrm{CS}$ & 0.0412 & \begin{tabular}{|ll|l|}
0.0082 & 0.0330
\end{tabular} & $\begin{array}{lll}0.0082 & 0.0330\end{array}$ \\
\hline $\mathrm{AR}(1)$ & 0.7400 & 0.73990 .0001 & 0.73490 .0051 \\
\hline ARMA-r $=0.25$ & 0.8870 & 0.88690 .0000 & 0.88460 .0023 \\
\hline ARMA-r $=0.5$ & 0.8242 & 0.82420 .0000 & 0.82090 .0033 \\
\hline ARMA-r $=0.8$ & 0.7206 & 0.72050 .0001 & 0.71510 .0055 \\
\hline \multirow{2}{*}{\multicolumn{2}{|c|}{$\sigma^{2}=1$}} & \multicolumn{2}{|c|}{ B } \\
\hline & & Same structure & Toeplitz \\
\hline$\Sigma$ & $L_{\Sigma, A}^{*}$ & \begin{tabular}{|ll}
$L_{A, B}^{*}$ & $L_{\Sigma, B}^{*}$ \\
\end{tabular} & $\begin{array}{ll}L_{A, B}^{*} & L_{\Sigma, B}^{*}\end{array}$ \\
\hline $\mathrm{CS}$ & 0.0268 & 0.00800 .0187 & 0.00800 .0187 \\
\hline $\mathrm{AR}(1)$ & 0.7396 & 0.73960 .0001 & 0.73410 .0055 \\
\hline ARMA-r $=0.25$ & 0.8874 & 0.88740 .0000 & 0.88510 .0022 \\
\hline ARMA-r $=0.5$ & 0.8265 & 0.82640 .0000 & 0.82310 .0034 \\
\hline ARMA-r $=0.8$ & 0.7206 & $\begin{array}{|ll|}0.7205 & 0.0001 \\
\end{array}$ & 0.71470 .0058 \\
\hline \multirow{2}{*}{\multicolumn{2}{|c|}{$\sigma^{2}=2$}} & \multicolumn{2}{|c|}{\begin{tabular}{|c|}
$\mathrm{B}$ \\
\end{tabular}} \\
\hline & & Same structure & Toeplitz \\
\hline$\Sigma$ & $L_{\Sigma, A}^{*}$ & $\begin{array}{|ll|}L_{A, B}^{*} & L_{\Sigma, B}^{*} \\
\end{array}$ & $L_{A, B}^{*} \quad L_{\Sigma, B}^{*}$ \\
\hline $\mathrm{CS}$ & 0.0359 & 0.00790 .0279 & 0.00790 .0279 \\
\hline $\mathrm{AR}(1)$ & 0.7413 & 0.74120 .0001 & 0.73560 .0057 \\
\hline ARMA-r $=0.25$ & 0.8872 & 0.88720 .0000 & 0.88500 .0022 \\
\hline ARMA-r $=0.5$ & 0.8249 & 0.82490 .0000 & 0.82160 .0033 \\
\hline ARMA-r $=0.8$ & 0.7216 & 0.72150 .0000 & 0.71640 .0052 \\
\hline \multirow{2}{*}{\multicolumn{2}{|c|}{$\sigma^{2}=4$}} & \multicolumn{2}{|c|}{ B } \\
\hline & & Same structure & Toeplitz \\
\hline$\Sigma$ & $L_{\Sigma, A}^{*}$ & \begin{tabular}{|ll}
$L_{A, B}^{*}$ & $L_{\Sigma, B}^{*}$ \\
\end{tabular} & $L_{A, B}^{*} \quad L_{\Sigma, B}^{*}$ \\
\hline $\mathrm{CS}$ & 0.0292 & 0.00820 .0210 & 0.00820 .0210 \\
\hline $\mathrm{AR}(1)$ & 0.7411 & 0.74110 .0001 & 0.73600 .0052 \\
\hline ARMA-r $=0.25$ & 0.8874 & 0.88740 .0000 & 0.88500 .0024 \\
\hline ARMA-r $=0.5$ & 0.8238 & 0.82370 .0001 & 0.82030 .0035 \\
\hline ARMA-r $=0.8$ & 0.7204 & 0.72030 .0001 & 0.71490 .0055 \\
\hline
\end{tabular}


Table 13 Simulation results with Toeplitz structure.

\begin{tabular}{|c|c|c|c|c|c|c|}
\hline \multirow{2}{*}{\multicolumn{2}{|c|}{$\sigma^{2}=0.50$}} & \\
\hline & & $\mathrm{MA}(1)$ & $\mathrm{CS}$ & $\mathrm{AR}(1)$ & $\operatorname{RMA}(1,1)$ & Toeplitz \\
\hline & $L_{\Sigma, A}^{*}$ & \begin{tabular}{ll|}
$L_{A, B}^{*}$ & $L_{\Sigma, B}^{*}$ \\
\end{tabular} & $\begin{array}{ll}L_{A, B}^{*} & L_{\Sigma, B}^{*}\end{array}$ & $\begin{array}{ll}L_{A, B}^{*} & L_{\Sigma, B}^{*}\end{array}$ & $\begin{array}{ll}L_{A, B}^{*} & L_{\Sigma, B}^{*}\end{array}$ & $\begin{array}{ll}L_{A, B}^{*} & L_{\Sigma, B}^{*}\end{array}$ \\
\hline $\mathrm{m}=10$ & 0.0775 & \begin{tabular}{|ll}
0.2049 & 0.1433
\end{tabular} & $\begin{array}{|ll|}0.1262 & 0.0695 \\
\end{array}$ & \begin{tabular}{|lll}
0.1202 & 0.0624
\end{tabular} & $\begin{array}{lll}0.0820 & 0.0281\end{array}$ & $\begin{array}{|ll|}0.0581 & 0.0194\end{array}$ \\
\hline & 0.1329 & $\begin{array}{lll}2685 & 0.15 \\
\end{array}$ & \begin{tabular}{|l|l|}
0.2177 & 0.0990 \\
\end{tabular} & $\begin{array}{|ll|}0.1837 & 0.06991\end{array}$ & 0.13360 .0181 & 0.11540 .0 \\
\hline & & 36370.0 & & & & \\
\hline$=100$ & 0.4876 & $\$ 106 \quad 0.0237$ & $5015 \quad 0.01$ & 0.50870 .0 & 280.0251 & \begin{tabular}{|lll}
0.4774 & 0.0102
\end{tabular} \\
\hline & 0.65 & 57030.01 & 56680.01 & $\begin{array}{lll}0.6695 & 0.4\end{array}$ & & .65000. \\
\hline & & 83520.00 & 8336000 & \begin{tabular}{|lll}
0.8352 & 0.0 \\
\end{tabular} & & 08050 \\
\hline 1000 & 0.9091 & $9100 \quad 0.00$ & $9095 \quad 0.0005$ & $0.9100 \quad 0.0009$ & 0.91010 .0009 & $\begin{array}{llll}0.9090 & 0.0001\end{array}$ \\
\hline \multirow{2}{*}{\multicolumn{2}{|c|}{$\sigma^{2}=1$}} & \\
\hline & & MA(1) & CS & AR(1) & ARMA $(1,1)$ & Toeplitz \\
\hline & $L_{\Sigma, A}^{*}$ & $\begin{array}{ll}L_{A, B}^{*} & L_{\Sigma, B}^{*} \\
\end{array}$ & $\begin{array}{ll}L_{A, B}^{*} & L_{\Sigma, B}^{*}\end{array}$ & $\begin{array}{ll}L_{A, B}^{*} & L_{\Sigma, B}^{*}\end{array}$ & $\begin{array}{ll}L_{A, B}^{*} & L_{\Sigma, B}^{*}\end{array}$ & $\begin{array}{ll}L_{A, B}^{*} & L_{\Sigma, B}^{*}\end{array}$ \\
\hline$=10$ & 0.0852 & 0.18480 .1169 & 0.10110 .0413 & 0.13650 .0768 & 0.12460 .0711 & $\begin{array}{lll}0.0635 & 0.0218\end{array}$ \\
\hline & & $2366 \quad 0.0827$ & $\begin{array}{lll}0.1801 & 0.0323\end{array}$ & $\begin{array}{lll}0.2253 & 0.0\end{array}$ & 0.26220 .1067 & $0.1400 \quad 0.0164$ \\
\hline & & 36840.06 & 33980.03 & 36110. & 0.2 & \begin{tabular}{|ll}
0.2959 & 0.0138 \\
\end{tabular} \\
\hline & 0 & 1200. & 1220 & 51150 & & .48430 .0100 \\
\hline & & 7010.0 & 66720. & 56960.4 & & 65280.0069 \\
\hline & & 460.0 & 380 & 83450. & & 3060.0014 \\
\hline 1000 & 0.90 & 90990.0010 & 90960 & \begin{tabular}{|ll}
0.9099 & 0.0
\end{tabular} & & .90870 .0002 \\
\hline \multirow{2}{*}{\multicolumn{2}{|c|}{$\sigma^{2}=2$}} & \multicolumn{5}{|c|}{$\mathrm{B}$} \\
\hline & & MA(1) & $\mathrm{CS}$ & $\mathrm{AR}(1)$ & ARMA $(1,1)$ & Toeplitz \\
\hline & $L_{\Sigma, A}^{*}$ & $\begin{array}{ll}L_{A, B}^{*} & L_{\Sigma, B}^{*} \\
\end{array}$ & $\begin{array}{ll}L_{A, B}^{*} & L_{\Sigma, B}^{*} \\
\end{array}$ & $\begin{array}{ll}L_{A, B}^{*} & L_{\Sigma, B}^{*} \\
\end{array}$ & $\begin{array}{ll}L_{A, B}^{*} & L_{\Sigma, B}^{*} \\
\end{array}$ & $\begin{array}{ll}L_{A, B}^{*} & L_{\Sigma, B}^{*} \\
\end{array}$ \\
\hline & & 0.14450 .0683 & $\begin{array}{llll}0.0956 & 0.0230 \\
\end{array}$ & 0.12820. & $\begin{array}{|ll|}0.1563 & 0.08 \\
\end{array}$ & 0.07140 .0194 \\
\hline & 0. & $081 \quad 0.06$ & 21950.0818 & 0.17410. & 220.01 & 0.14180 .0070 \\
\hline & & $557 \quad 0.0$ & 39990.02 & 35210. & 20.0427 & $0.3068 \quad 0.0140$ \\
\hline & & & & & 0. & \begin{tabular}{|lll}
0.4820 & 0.0103
\end{tabular} \\
\hline & & 57270.0096 & 57590 & $0.6726 \quad 0.0$ & 0.67330 .0 & \begin{tabular}{|ll}
0.6563 & 0.0068
\end{tabular} \\
\hline & & 3520.0 & 3370 & 83510.4 & & 0.82960 .0014 \\
\hline & & 0990.0010 & 0950 & $\begin{array}{lll}0.9099 & 0.0 \\
\end{array}$ & & \\
\hline \multirow{2}{*}{\multicolumn{2}{|c|}{$\sigma^{2}=4$}} & \multicolumn{5}{|c|}{$\mathrm{B}$} \\
\hline & & & CS & $\mathrm{AR}(1)$ & ARMA $(1,1)$ & Toeplitz \\
\hline & & $\begin{array}{ll}L_{A, B}^{*} & L_{\Sigma, B}^{*} \\
\end{array}$ & $\begin{array}{ll}L_{A, B}^{*} & L_{\Sigma, B}^{*} \\
\end{array}$ & $\begin{array}{ll}L_{A, B}^{*} & L_{\Sigma, B}^{*} \\
\end{array}$ & $\begin{array}{ll}L_{A, B}^{*} & L_{\Sigma, B}^{*} \\
\end{array}$ & $\begin{array}{ll}L_{A, B}^{*} & L_{\Sigma, B}^{*} \\
\end{array}$ \\
\hline$=10$ & 0.0664 & 0.27420 .2150 & $0.1093 \quad 0.0656$ & 0.12330 .0828 & 0.0684 & $0.0492 \quad 0.0172$ \\
\hline & 0.1540 & 0.24620 .0960 & $\begin{array}{lll}0.1886 & 0.0462\end{array}$ & 0.22390 .0765 & 0.28070 .1302 & $\begin{array}{lll}0.1368 & 0.0172\end{array}$ \\
\hline & & $\begin{array}{lll}43 & 0.06 \\
\end{array}$ & & & & $\begin{array}{lll}0.2962 & 0.0137\end{array}$ \\
\hline & & 510. & 49940. & 51440.0 & 0.51 & \begin{tabular}{|ll}
0.4783 & 0.0107
\end{tabular} \\
\hline & & & $\begin{array}{lll}0.6764 & 0.0 \\
\end{array}$ & \begin{tabular}{|lll}
0.6728 & 0.0 \\
\end{tabular} & & 0.656990 .0067 \\
\hline & & & & & & \\
\hline & & & & & & \\
\hline
\end{tabular}

